doi: 10.2306/scienceasia1513-1874.2014.40.393

\title{
Molluscicidal activity of Camellia oleifera seed meal
}

\author{
Supunsa Kijprayoon ${ }^{\mathrm{a}}$, Vasana Tolieng ${ }^{\mathrm{b}}$, Amorn Petsom ${ }^{\mathrm{a}}$, Chanya Chaicharoenpong ${ }^{\mathrm{b}, *}$ \\ a Research Centre for Bioorganic Chemistry, Department of Chemistry, Faculty of Sciences, \\ Chulalongkorn University, Bangkok 10330 Thailand \\ b Institute of Biotechnology and Genetic Engineering, Chulalongkorn University, Bangkok 10330 Thailand \\ *Corresponding author, e-mail: chanya.c@chula.ac.th
}

Received 6 Jul 2013

Accepted 1 Dec 2014

\begin{abstract}
A mixture of molluscicidal saponin compounds was isolated from a methanolic extract of seed meal of Camellia oleifera and tested against Pomacea canaliculata. The most potent saponin fraction showed an $\mathrm{LC}_{50}$ value of $0.66 \mathrm{ppm}$. This was then used as a marker for quantitative analysis of active molluscicidal compounds in commercial oilseed camellia meals on HPLC fractionation. The active saponin content was found to be $0.25-1.26 \% \mathrm{w} / \mathrm{w}$. Methanol was the preferred extraction solvent for analysis of saponin compounds from oil-seed camellia meal. The effect of oil-seed camellia meal on $P$. canaliculata in a field experiment was determined for three doses: $12.50,15.63$, and $18.75 \mathrm{~kg} / \mathrm{ha}$ in terms of numbers of dead snails. After one day, all treatments containing oil-seed camellia meal killed $100 \%$ of the snails in the sample compared with just $3.8 \%$ in the control without any chemical additive. No rice plant damage was detected from any treatments with oil-seed camellia meal, and the dry grain yield was comparable to that of niclosamide treatment. Thus oil-seed camellia meals may be a useful molluscicide for organic rice production.
\end{abstract}

KEYWORDS: tea oil camellia, Pomacea canaliculata, saponin, rice technology, organic farming

\section{INTRODUCTION}

The oil-seed camellia tree, or tea oil camellia tree, Camellia oleifera Abel. (Ericales: Theaceae), is an important source of seed oil in China ${ }^{1}$, where it is extensively cultivated in southern region and found in forests. The oil, obtained from plant seeds, is used for cooking, hair-dressing, the treatment of intestinal disorders, burns and skin diseases, ringworm, high blood LDL levels, and even coating ferric metal tools to prevent rusting ${ }^{2,3}$. Defatted seed meal contains a large amount of underutilized saponin compounds, and it has been used extensively in aquaculture to eliminate predaceous fish in shrimp ponds ${ }^{4}$ to prevent the loss of functions, regulate ion balance and osmotic pressure of respiratory organs ${ }^{5}$.

The native habitat of the golden apple snail, Pomacea canaliculata Lamark. (Architaenioglossa: Ampullariidae) is in the Amazon interior and La Plata basins of South America ${ }^{6}$, but this species, regarded as a highly invasive species, has been widely distributed across the globe by human activity. It was first introduced to Asia for human consumption and as an exotic pet ${ }^{7}$. The snails were released uncontrolled to rivers, and they later spread into rice fields where they have become a serious threat to rice production, as they can consume an entire paddy field of young rice plants overnight. Consequentially, synthetic molluscicides (e.g., $\mathrm{CuSO}_{4}$, metaldehyde, and niclosamide) are widely used to control snail populations in rice fields ${ }^{8}$. These broad acting non-specific molluscicidal agents are however extremely toxic to non-target organisms, including humans and to the environment in addition to adding considerable costs to the farmers ${ }^{9}$. For humans, the side effects of these currently used agrochemical based molluscicides can include blurred vision, blindness, skin problems, headaches, and the loss of toenails and fingernails. Natural molluscicides taken from plant extracts may have less undesirable effects upon humans and the environment. Thus they are gaining greater attention because they are considered safer and more ecologically suitable for snail control. Currently, they are considered to be effective, biodegradable, and economical enough to be employed on a large scale.

In recent years, oil-seed camellia meal has been used extensively for the elimination of golden apple snails in rice fields in Thailand. The molluscicidal activity of the water extract of defatted oil-seed camellia cake against the golden apple snail was reported to have an $\mathrm{LC}_{50}$ values of $21.5,42.1$, and $48.8 \mathrm{mg} / \mathrm{l}$ for snails of size 5-20 mm, 21-35 mm, and $36-50 \mathrm{~mm}$, respectively ${ }^{10}$. For quality control, the quantitative determination of saponin compounds 
in oil-seed camellia meal is required. However, only quantitative TLC analysis of total saponin compounds has been reported ${ }^{11}$. The commercial application of oil-seed camellia meal as a molluscicide agent has increased tremendously. An effective measurement of active compounds in oil-seed camellia meal is therefore urgently required to determine the optimal raw material and product qualifications. Since oilseed camellia meal is a natural product, the active content will likely depend on the variety of the plant, geographical location, and culture conditions as well as seasonal changes. It is therefore urgent to determine the active ingredients, as these can then be used as markers for selecting suitable cultivars and optimizing the culture and extraction conditions, as well as optimizing future production quality control.

This study describes the isolation, identification, and molluscicidal activity of active compounds from the methanolic extract of oil-seed camellia meal. A comparison of molluscicidal activity with known synthetic compounds is reported, as well as the quantitative analysis of oil-seed camellia meal by highperformance liquid chromatography (HPLC) fractionation. In addition, the test of oil-seed camellia meal on the golden apple snail in paddy fields and phytotoxic effects to rice plant are reported. This study also investigates the dry grain yield following treatments that applied oil-seed camellia meal, a treatment with niclosamide, and a non-chemical compound.

\section{MATERIALS AND METHODS}

\section{Experimental materials}

Oil-seed camellia meal was purchased from the Hangzhou Choisun Tea Sci-Tech Co. Ltd., Zhejiang province, China as defatted seed of $C$. oleifera. Golden apple snails $(3.5-5.0 \mathrm{~cm}$ shell length and 12-15 g weight) were collected from organic rice fields in Wangnoi district, Ayuthaya province, Thailand. All organic solvents including those used for HPLC were of HPLC grade and were purchased from Merck Co. Ltd., Germany. Niclosamide and metaldehyde were purchased from Bayerthai Co. Ltd., Thailand and Sotus International Co. Ltd., Thailand, respectively. Diaion HP-20 was purchased from Mitsubishi Chemical Corporation, Tokyo. TLC plates were silica gel 60 F254 (Merck, 0.25 mm).

\section{Instrumentation and chromatographic conditions}

Diaion HP-20 was used for column chromatography. Resolved TLC plates were visualized by spraying with $p$-anisaldehyde in sulphuric acid, before heating on a hot plate. HPLC separation was performed on a Thermo Finnigan apparatus with SpectraSYSTEM UV-detector (Thermo Separation Products Inc., Piscataway, NJ), equipped with Phenomenex Luna $\mathrm{C}_{18}$ column $(250 \mathrm{~mm} \times 4.60 \mathrm{~mm} \mathrm{ID}, 5 \mu \mathrm{m}$, Phenomenex, Torrance, CA) and Hyperprep HS $\mathrm{C}_{18}$ column $(250 \times 10 \mathrm{~mm}$ ID, $12 \mu \mathrm{m}$, Thermo Electron Corp., Bellefonte, PA). UV detection was carried out at $235 \mathrm{~nm}$. Infrared (IR) spectra were recorded using a Nicolet Impact 410 spectrometer on $\mathrm{KBr}$ pellet (Nicolet Instruments Corporation, Madison, WI). Mass spectra were measured on MALDI-TOF model of Bruker Daltonics mass spectrometer (Bruker Daltonics Inc., Billerica, MA).

\section{Extraction and isolation}

Ground and dried oil-seed camellia meal $(1 \mathrm{~kg})$ was soaked in methanol $(2.51 \times 3)$ for $24 \mathrm{~h}$. The three solvent fractions were then pooled and evaporated under low pressure to obtain a residue $(113.9 \mathrm{~g} ; 11 \%)$. An aliquot of the residue (12.39 g) was suspended in water $(100 \mathrm{ml})$ and then partitioned with chloroform $(50 \mathrm{ml} \times 3)$ followed by $n$-butanol $(50 \mathrm{ml} \times 3)$ at room temperature. Partitioned layers of each solvent were pooled together and concentrated on a rotary vacuum evaporator, yielding $2.11 \mathrm{~g}$ from the chloroform extract (17\%), $0.90 \mathrm{~g}$ from the $n$-butanol extract (7\%), and $9.38 \mathrm{~g}$ from the water extract $(76 \%)$. The $n-\mathrm{BuOH}$ extract $(0.90 \mathrm{~g})$ was chromatographed in a Diaion HP-20 porous polymer resin column $(25 \mathrm{~cm} \times 4.5 \mathrm{~cm}$ ID). The column was eluted with $550 \mathrm{ml}$ of water (0\%), 30\%, 50\%, 70\%, and 100\% (v/v) aq. $\mathrm{MeOH}$, successively, before collecting $25 \mathrm{ml}$ per fraction. Each fraction was then analysed by TLC. Five fractions (A-E) were obtained. The fraction with the highest activity, fraction $\mathrm{D}$, was further purified by HPLC on Hyperprep HS $\mathrm{C}_{18}$ column $(250 \times 10 \mathrm{~mm}$ ID, $12 \mu \mathrm{m})$ with $40 \%(\mathrm{v} / \mathrm{v}) \mathrm{MeOH}$ in $0.1 \%(\mathrm{v} / \mathrm{v})$ aq. acetic acid as the mobile phase at a flow rate of $1.4 \mathrm{ml} / \mathrm{min}$. UV detection was carried out at $235 \mathrm{~nm}$. Fraction D4 was obtained as a colourless fine powder compound ( $6.0 \mathrm{mg}, 0.67 \%)$, an MS: $m / z$ : $1226-1338$ with an $R_{\mathrm{f}}$ value of 3.8 in a $6: 2: 1(\mathrm{v} / \mathrm{v} / \mathrm{v})$ ratio mixture of ethyl acetate:methanol:water as the mobile solvent. The crude extract and its subsequent fractions were tested for molluscicidal activity against P. canaliculata.

\section{Molluscicidal assay}

The molluscicidal activity of oil-seed camellia meal extracts was tested against golden apple snails, $P$. canaliculata, according to the protocol of World Health Organization ${ }^{12}$. The snails used in this study were $3.5-5.0 \mathrm{~cm}$ in shell diameter and weighed ap- 
proximately $12-15 \mathrm{~g}$ each. The snails were acclimated to laboratory conditions after arrival for a week and fed Neptunia oleracea Lour. and leaves of Musa sapientum Linn. The synthetic chemical molluscicides, niclosamide $70 \%$ wettable powder (WP) and metaldehyde $80 \%$ WP, were used as reference standards for comparison. Five different concentrations of each compound were tested, each with three replicates of 10 snails. Snails were put in 11 plastic jars containing $300 \mathrm{ml}$ of testing solution for $24 \mathrm{~h}$. The control treatment was dechlorinated water. The jars were then covered with a nylon net and secured with a rubber band to prevent the snails from escaping. The snails were fed during treatment. Dead snails were determined by probing with a needle to observe their response.

\section{Statistical analysis}

The percentage mortality was corrected by Abbott's formula ${ }^{13}$. If the cumulative mortality in the control replications was between 5 and $20 \%$, the mortality percentage $(M)$, according to Abbott's formula was as follows:

$$
M=\frac{M_{\mathrm{t}}-M_{\mathrm{c}}}{100-M_{\mathrm{c}}}
$$

where $M_{\mathrm{t}}$ is the percentage of dead snails in the extract or chemical solution after $24 \mathrm{~h}$ of treatment, and $M_{\mathrm{c}}$ is the percentage of dead snails in dechlorinated water at $24 \mathrm{~h}$ of treatment.

Any assay in which control replications had a cumulative mortality of more than $20 \%$ was declared void and repeated. The cumulative mortality of snails after $24 \mathrm{~h}$ of treatment was analysed by Probit analysis ${ }^{14}$ using SPSS software (version 13).

\section{Quantitative analysis of saponin compounds by HPLC}

Fraction D4 was used as a standard saponin for quantitative determination. HPLC analysis was performed using a mixture of $40 \%(\mathrm{v} / \mathrm{v})$ methanol in $0.1 \%(\mathrm{v} / \mathrm{v})$ aq. acetic acid as a mobile phase, with a flow rate of $0.8 \mathrm{ml} / \mathrm{min}$. UV detection was carried out at $235 \mathrm{~nm}$. Triplicate injections of each concentration, ranging from 10-200 ppm, were done. A calibration curve was constructed from the relationships between the value of the peak area (mAU) and the amount of fraction D4 injected (ppm). Analysis of saponin content in commercial oil-seed camellia meals was carried out using the methanol and water extracts of the samples.

\section{Field experiments}

Field trials were conducted in paddy fields at Si Prachan and Don Chedi districts, Suphanburi

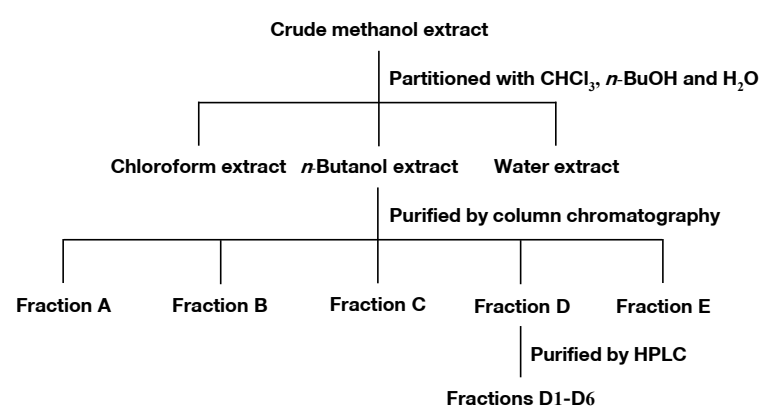

Fig. 1 Schematic diagram of oil-seed camellia meal extraction.

province, Thailand during February-June 2011. Twenty paddy blocks were prepared, each with an area of approximately $10 \mathrm{~m}^{2}$. The water level was about $5 \mathrm{~cm}$. Twenty-day-old rice seedlings (Oryza sativa Linn., variety SPR1) were transplanted $20 \mathrm{~cm}$ apart. The treatments were arranged in a complete randomized block design with four replications and five treatments. Twenty golden apple snails were placed in each field 10 days after rice was transplanted. Then the chemicals were applied to the paddy fields by sowing. The treatment chemicals were defatted oil-seed camellia meal at $12.50 \mathrm{~kg} / \mathrm{ha}$, $15.63 \mathrm{~kg} / \mathrm{ha}$, and $18.75 \mathrm{~kg} / \mathrm{ha}$. Niclosamide $(70 \%$ $\mathrm{WP}, 0.31 \mathrm{~kg} / \mathrm{ha}$ ) was sprayed as a positive control treatment in addition to a non-chemical treatment. The number of dead snails and damaged rice plants was recorded after the treatment of chemicals for 1, 2, 7, and 15 days. All treatments received the same amount of fertilizers. Urea $(187.5 \mathrm{~kg} / \mathrm{ha})$ and ammonium phosphate $(187.5 \mathrm{~kg} / \mathrm{ha})$ were applied at 25 and 75 days after transplanting by sowing, respectively. The experiment blocks were monitored until the grain was harvested, and the weight of dry grain was recorded. Experimental design and crop management were identical for all fields. Data were analysed statistically with Dunnett's test using SPSS.

\section{RESULTS}

\section{Isolation and molluscicidal activity}

The crude methanol extract of oil-seed camellia meal was partitioned with chloroform, $n$-butanol, and water, respectively, (Fig. 1), and then tested for molluscicidal activity against golden apple snails, $P$. canaliculata (Table 1). Results show that $n$-butanol extract had the highest molluscicidal activity, with an $\mathrm{LC}_{50}$ of $6.79 \mathrm{ppm}$. The $n$-butanol extract was further purified using Diaion HP-20 column chromatography. Five fractions (A-E) were eluted from column with 0, 30, 50, 70, and $100 \%$ (v/v) aq. methanol, respectively. 
Table 1 Molluscicidal activities of oil-seed camellia meal extracts, partitioned crude extracts and the agrochemical molluscicides, niclosamide and metaldehyde, against P. canaliculata.

\begin{tabular}{lc}
\hline Samples & $\mathrm{LC}_{50}{ }^{*}(\mathrm{ppm})$ \\
\hline crude methanol extract & 9.20 \\
chloroform extract & 7.43 \\
$n$-butanol extract & 6.79 \\
water extract & 14.01 \\
fraction A & $>100$ \\
fraction B & $>100$ \\
fraction C & $>100$ \\
fraction D & 6.52 \\
fraction E & 20.92 \\
fraction D4 & 0.66 \\
niclosamide $(70 \% \mathrm{WP})$ & 0.27 \\
metaldehyde $(80 \% \mathrm{WP})$ & 34.98 \\
\hline
\end{tabular}

${ }^{*} \mathrm{LC}_{50}$ is the lethal concentration (ppm) that kills $50 \%$ of the snails with average of three replications.

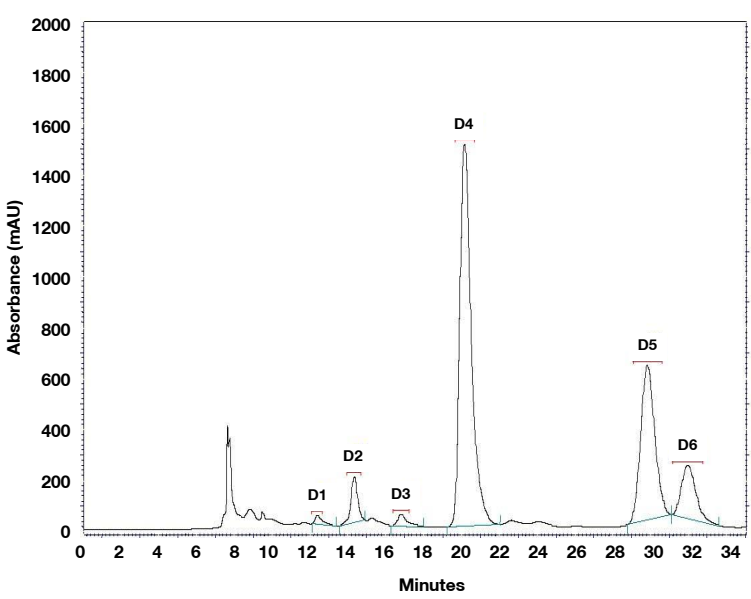

Fig. 2 HPLC chromatogram of fraction D using a Hyperprep $\mathrm{HS} \mathrm{C}_{18}$ column with $40 \%$ (v/v) methanol in $0.1 \%$ $(\mathrm{v} / \mathrm{v})$ aq. acetic acid as the mobile phase and a flow rate of $1.4 \mathrm{ml} / \mathrm{min}$, at $235 \mathrm{~nm}$.

These were then tested for molluscicidal activity (Table 1). Fractions D and E exhibited molluscicidal activity; whereas, fractions $\mathrm{A}, \mathrm{B}$, and $\mathrm{C}$ did not show any molluscicidal activity, at least in this assay at concentrations below $100 \mathrm{ppm}$. Fraction D, eluted by $70 \%(\mathrm{v} / \mathrm{v})$ aq. methanol, was the most active compound with an $\mathrm{LC}_{50}$ of $6.52 \mathrm{ppm}$, and was further purified by HPLC on Hyperprep HS $\mathrm{C}_{18}$ column. The major component of fraction $\mathrm{D}$ was separated as fraction D4 with a retention time of $20.40 \mathrm{~min}$ (Fig. 2). Fraction D4 exhibited an $\mathrm{LC}_{50}$ of $0.66 \mathrm{ppm}$ when tested for molluscicidal activity. Then fraction D4 was
Table 2 Fraction D4 content (\% w/w \pm SD of triplicate analysis) in commercial oil-seed camellia meals, extracted with methanol or water.

\begin{tabular}{lccc}
\hline \multirow{2}{*}{$\begin{array}{l}\text { Extraction } \\
\text { solvent }\end{array}$} & \multicolumn{3}{c}{$\%$ Fraction D4 content $(\% \mathrm{w} / \mathrm{w} \pm \mathrm{SD})$} \\
\cline { 2 - 4 } & Sample 1 & Sample 2 & Sample 3 \\
\hline methanol & $0.43 \pm 0.01$ & $1.02 \pm 0.02$ & $1.26 \pm 0.02$ \\
water & $0.25 \pm 0.02$ & $0.78 \pm 0.02$ & $1.07 \pm 0.02$ \\
\hline
\end{tabular}

subjected to structural identification using infrared spectroscopy and MALDI-TOF mass spectrometry.

\section{Identification}

The IR absorption spectrum of the isolated fraction D4 showed absorption bands at 1761 and $1546 \mathrm{~cm}^{-1}$, assigned to carbonyl and $\alpha, \beta$-unsaturated ester functions. It also showed broad bands at 3134 and $1082 \mathrm{~cm}^{-1}$, suggestive of a glycoside structure. The results of MALDI-TOF mass spectrum suggested a molecular weight of $1226-1338 \mathrm{~m} / \mathrm{z}$.

\section{Quantitative analysis of saponin compounds}

Quantitative determination of the saponin compounds in oil-seed camellia meal was investigated by reverse phase HPLC. Purified fraction D4, representing active molluscicidal substances in the extract, was used as a saponin standard marker. The standard plot of fraction D4 concentrations and peak area was a linear regression plot with a correlation coefficient of 0.9997 , supporting a strongly correlated linear relationship, making it suitable for employing the attained HPLC peak area as an estimate for the actual concentration under these assay conditions.

Oil-seed camellia meal products were extracted by methanol or water. Three commercial samples of oil-seed camellia meals were tested, and the amount of saponin compounds, relative to fraction D4, detected in samples is shown in Table 2. Representative HPLC chromatograms of the methanolic and water extracts of oil-seed camellia meal are shown in Fig. 3a and 3b, respectively. The peak of fraction D4 in the crude oilseed camellia meal extract was confirmed by spiking the crude extract with a previously isolated fraction of D4.

\section{Field experiments}

The results for percentage of dead snail in a paddy field at Si Prachan and Don Chedi districts in Suphanburi province are shown in Table 3. The percentage of dead snails when treated with oil-seed camellia meal after 1, 2, 7, and 15 days was $100 \%$, the same as with the niclosamide treatment in a paddy field 

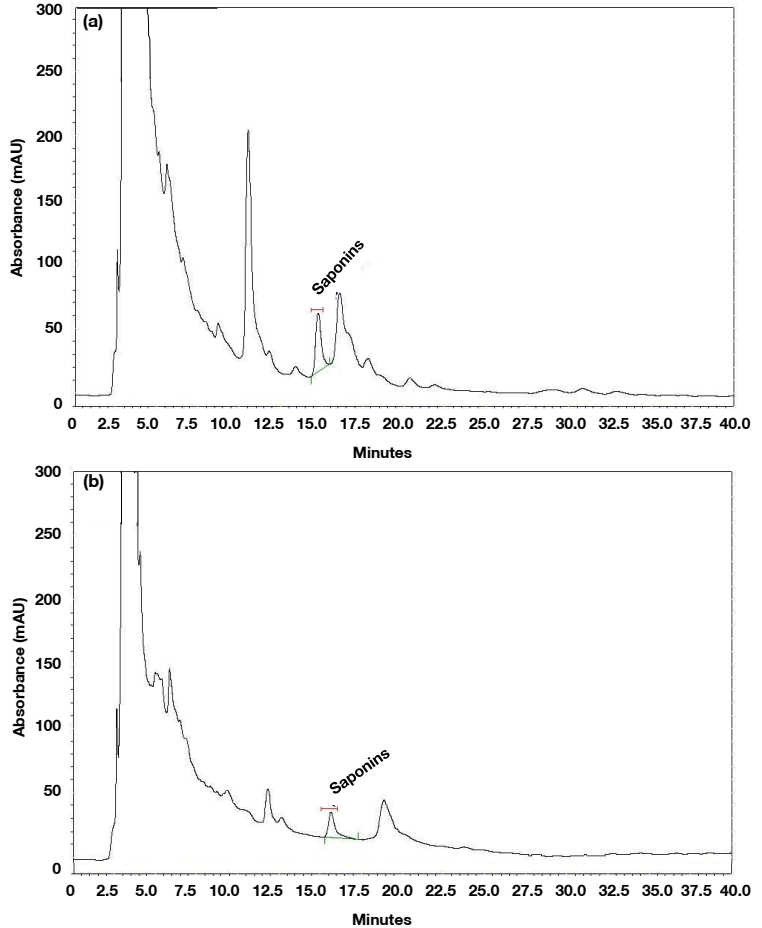

Fig. 3 HPLC chromatogram of (a) methanol extract and (b) water extract of oil-seed camellia meal using a Phenomenex Luna $\mathrm{C}_{18}$ column with $40 \%$ (v/v) methanol in $0.1 \%(\mathrm{v} / \mathrm{v})$ aq. acetic acid as the mobile phase and a flow rate of $0.8 \mathrm{ml} / \mathrm{min}$, at $235 \mathrm{~nm}$.

at Si Prachan district (Table 3). The percentage of dead snails in the control treatment was $3.8 \%$ after 1, 2, 7, and 15 days (Table 3 ). These results were in agreement with the data of field experiments at Don Chedi district. The percentage of damaged rice plant when treated with oil-seed camellia meal and niclosamide after $1,2,7$, and 15 days in both areas was $0 \%$ (Table 3). In comparison with the non-treated control, the percent of damaged rice plant in control experiments was 5\% and 7\% after $24 \mathrm{~h}$ at $\mathrm{Si}$ Prachan and Don Chedi districts, respectively. The percentage of damaged rice plant in both control experiment areas increased over time (Table 3). Weight of the dry grain of the control experiment was 3.88-4.69 t/ha, while weight of the dry grain of the treatments with oil-seed camellia meal was 5.69-7.38 t/ha. The niclosamide treatment produced $7.06-7.19 \mathrm{t} / \mathrm{ha}$ of dry grain.

\section{DISCUSSION}

Crude methanol extract of oil-seed camellia meal exhibited molluscicidal activity with an $\mathrm{LC}_{50}$ of $9.20 \mathrm{ppm}$ against golden apple snails, but it was 34-fold less effective than niclosamide (70\% WP, $\mathrm{LC}_{50}$ of $0.27 \mathrm{ppm}$ ) and 3.8-fold more effective than metaldehyde (80\% WP, $\mathrm{LC}_{50}$ of $34.98 \mathrm{ppm}$ ). Chloroform, $n$-butanol, and water extracts that formed the partitioned layer of crude methanol extract showed molluscicidal activity against golden apple snails with an $\mathrm{LC}_{50}$ of $7.43,6.79$, and $14.01 \mathrm{ppm}$, respectively. Fraction D4, which was purified from fraction D of the $n$-butanol extract from a crude methanolic extract of oil-seed camellia meal, was the most potent tested compound from the oil-seed camellia ( $C$. oleifera) meal against golden apple snails. With an $\mathrm{LC}_{50}$ of $0.66 \mathrm{ppm}$, it was approximately 44 -fold more effective than metaldehyde ( $80 \% \mathrm{WP}, \mathrm{LC}_{50}$ of $34.98 \mathrm{ppm}$ )

Table 3 Results of field treatments at two locations.

\begin{tabular}{|c|c|c|c|c|c|c|c|c|c|}
\hline \multirow[t]{2}{*}{ Treatment } & \multicolumn{4}{|c|}{$\%$ dead snails } & \multicolumn{4}{|c|}{$\%$ damaged rice } & \multirow{2}{*}{$\begin{array}{l}\text { Weight of dry } \\
\text { grain rice }(t / h a)\end{array}$} \\
\hline & $1 \mathrm{~d}$ & $2 \mathrm{~d}$ & $7 \mathrm{~d}$ & $15 \mathrm{~d}$ & $1 \mathrm{~d}$ & $2 \mathrm{~d}$ & $7 \mathrm{~d}$ & $15 \mathrm{~d}$ & \\
\hline \multicolumn{10}{|l|}{ Si Prachan district } \\
\hline Control & $3.8^{\mathrm{a}}$ & $3.8^{\mathrm{a}}$ & $3.8^{\mathrm{a}}$ & $3.8^{\mathrm{a}}$ & $5.2^{\mathrm{a}}$ & $10.2^{\mathrm{a}}$ & $18.0^{\mathrm{a}}$ & $39.7^{\mathrm{a}}$ & $3.88^{\mathrm{a}}$ \\
\hline OSM $12.50 \mathrm{~kg} / \mathrm{ha}$ & $100^{\mathrm{b}}$ & $100^{\mathrm{b}}$ & $100^{\mathrm{b}}$ & $100^{\mathrm{b}}$ & $0^{\mathrm{b}}$ & $0^{\mathrm{b}}$ & $0^{\mathrm{b}}$ & $0^{\mathrm{b}}$ & $5.69^{\mathrm{b}}$ \\
\hline OSM $15.63 \mathrm{~kg} / \mathrm{ha}$ & $100^{\mathrm{b}}$ & $100^{\mathrm{b}}$ & $100^{\mathrm{b}}$ & $100^{\mathrm{b}}$ & $0^{\mathrm{b}}$ & $0^{\mathrm{b}}$ & $0^{\mathrm{b}}$ & $0^{\mathrm{b}}$ & $6.44^{\mathrm{b}}$ \\
\hline OSM $18.75 \mathrm{~kg} / \mathrm{ha}$ & 100 & $100^{\mathrm{b}}$ & $100^{\mathrm{a}}$ & $100^{\mathrm{b}}$ & $0^{\mathrm{b}}$ & $0^{\mathrm{b}}$ & $0^{\mathrm{b}}$ & $0^{\mathrm{b}}$ & $6.94^{\mathrm{b}}$ \\
\hline NCS 0.31 kg/ha & $100^{\mathrm{a}}$ & $100^{\mathrm{a}}$ & $100^{\mathrm{b}}$ & $100^{\mathrm{b}}$ & $0^{\mathrm{b}}$ & $0^{\mathrm{b}}$ & $0^{\mathrm{b}}$ & $0^{\mathrm{b}}$ & $7.19^{\mathrm{b}}$ \\
\hline \multicolumn{10}{|l|}{ Don Chedi district } \\
\hline Control & $3.8^{\mathrm{a}}$ & $3.8^{\mathrm{a}}$ & $5.0^{\mathrm{a}}$ & $5.0^{\mathrm{a}}$ & $7.0^{\mathrm{a}}$ & $14.1^{\mathrm{a}}$ & $25.7^{\mathrm{a}}$ & $52.7^{\mathrm{a}}$ & $4.69^{\mathrm{a}}$ \\
\hline OSM $12.50 \mathrm{~kg} / \mathrm{ha}$ & $96.3^{\mathrm{b}}$ & $100^{\mathrm{b}}$ & $100^{\mathrm{b}}$ & $100^{\mathrm{b}}$ & $0^{\mathrm{b}}$ & $0^{\mathrm{b}}$ & $0^{\mathrm{b}}$ & $0^{\mathrm{b}}$ & $6.50^{\mathrm{b}}$ \\
\hline OSM $15.63 \mathrm{~kg} / \mathrm{ha}$ & $100^{\mathrm{b}}$ & $100^{\mathrm{b}}$ & $100^{\mathrm{b}}$ & $100^{\mathrm{b}}$ & $0^{\mathrm{b}}$ & $0^{\mathrm{b}}$ & $0^{\mathrm{b}}$ & $0^{\mathrm{b}}$ & $6.69^{\mathrm{b}}$ \\
\hline OSM $18.75 \mathrm{~kg} / \mathrm{ha}$ & $98.8^{\mathrm{b}}$ & $100^{\mathrm{b}}$ & $100^{\mathrm{b}}$ & $100^{\mathrm{b}}$ & $0^{\mathrm{b}}$ & $0^{\mathrm{b}}$ & $0^{\mathrm{b}}$ & $0^{\mathrm{b}}$ & $7.38^{\mathrm{b}}$ \\
\hline NCS $0.31 \mathrm{~kg} / \mathrm{ha}$ & $98.8^{\mathrm{b}}$ & $100^{\mathrm{b}}$ & $100^{\mathrm{b}}$ & $100^{\mathrm{b}}$ & $0^{\mathrm{b}}$ & $0^{\mathrm{b}}$ & $0^{\mathrm{b}}$ & $0^{\mathrm{b}}$ & $7.06^{\mathrm{b}}$ \\
\hline
\end{tabular}

OSM = oil-seed camellia meal; NCS = niclosamide (70\% WP)

Different letters within the same column indicate significant differences (Dunnett's test, $p \leqslant 0.05$ ) 
and only approximately 2.4 -fold less effective than niclosamide (70\% WP, $\mathrm{LC}_{50}$ of $0.27 \mathrm{ppm}$ ). Saponin compounds extracted from the pericarp of soapnuts, Sapindus mukorossi, a natural plant molluscicide, was reported to exhibit molluscicidal activity against golden apple snails with an $\mathrm{LC}_{50}$ value approximately 9 -fold higher than that found here, being $85 \mathrm{ppm}$ when exposed for $24 \mathrm{~h}^{15}$ compared to the $9.20 \mathrm{ppm}$ observed here for the crude methanol extract of oil-seed camellia meal (Table 1). Accordingly, the saponin extract of $C$. oleifera is a more potent molluscicide than that of $S$. mukorossi.

The isolated fraction D4 was identified by comparison of its physical data with the reported values ${ }^{16-24}$. The saponin compounds in Camellia spp. have a molecular weight between 1100 and $1400 \mathrm{~m} / z$. From the spectrometric data obtained in this study, fraction D4 was elucidated as a mixture of saponin compounds. Fraction D4 formed a honeycomb shaped froth after shaking and settling for $30 \mathrm{~min}$. It produced a pink-reddish solution with the LiebermannBurchard test supporting that fraction D4 was a mixture of saponin compounds. The identity of each individual saponin in fraction D4 is currently being characterized and will be reported elsewhere.

Analysis of the saponin content in commercial oil-seed camellia meals was carried out on methanol and water extracts of samples to investigate suitable extraction solvents for further analysis. Methanol and water were selected, as these are solvents commonly used to extract saponin compounds but water is less efficient extraction solvent ${ }^{25}$. Accordingly, methanol extracts gave higher yields of total saponin compounds than the corresponding water extracts (Table 2). Methanol is therefore considered the preferred solvent to extract saponin compounds from oilseed camellia.

A water extract of defatted oil-seed camellia meal was reported to exhibit an $\mathrm{LC}_{50}$ of $48.8 \mathrm{mg} / \mathrm{l}$ for snails of size $36-50 \mathrm{~mm}^{10}$, which is less effective than the crude methanolic extract of oil-seed camellia meal observed in this study, with an $\mathrm{LC}_{50}$ of $9.20 \mathrm{ppm}$ for the same size of snails (Table 1). This apparent enhanced biological activity could suggest that methanol can dissolve tea saponin compounds better than water, thus exhibiting more potent activity, or it may solvate a different group of saponin compounds. Haemolysis process of Ficus platyphylla with two solvents: methanol and water also exhibited the same results that methanol was a better solvent for saponin compounds than water ${ }^{26}$. Haemolysis duration for methanol was also shorter than water as solvent for the ground samples of $F$. platyphylla.
Field experiments were conducted with oil-seed camellia meal that contained fraction D4 as $0.43 \%$ $\mathrm{w} / \mathrm{w}$ (Table 2). The results show that the lowest concentration of oil-seed camellia meal, $12.5 \mathrm{~kg} / \mathrm{ha}$, used in this experiment could control the golden apple snail when compared with that of niclosamide, which causes $100 \%$ mortality of the snails within $24 \mathrm{~h}$. Moreover, it was observed that the rice experienced no change in either in growth, date of flowering, maturation, or weight of dry grain when treated with oil-seed camellia meal or niclosamide. Table 3 shows that there were no significant effects on the weight of dry grain as a result of the treatment. These results do confirm the use of oil-seed camellia meal to control golden apple snail in rice paddies and can help farmers to achieve quality environmental pest management and avoid unnecessary sprays of chemical pesticides. Thus organic rice production would benefit from the results of this study.

Acknowledgements: The authors wish to express their gratitude to Suree Thangprom, Chompunut Janyated and Dr Petcharut Chuntaratin for their advice and comments. This work was financially supported by grants from the Graduate School of Chulalongkorn University and the Industrial Research and Development Unit, Institute of Biotechnology and Genetic Engineering, Chulalongkorn University.

\section{REFERENCES}

1. Yu YS, Ren SX, Tan KY (1999) Study on climatic regionalization and layer and belt distribution of oiltea camellia quality in China. $J$ Nat Resour 14, 123-7. (in Chinese).

2. Jiangsu New Medical College (1977) Dictionary of Chinese Traditional Medicine, People's Publishing House, Shanghai, p 1054.

3. Perry LM, Metzger J (1980) Medicinal Plants of East and Southeast Asia, MIT Press, Cambridge, p 403.

4. Tang YA (1961) The use of saponin to control predaceous fish in shrimp ponds. Prog Fish Cult 23, 43-5.

5. Hostettmann K, Marston A (2005) Saponins. Chemistry and Pharmacology of Natural Products, Cambridge Univ Press, Cambridge, pp 250-2.

6. Lamarck JBPA (1822) Histoire Naturelle des Animaux Sans Vertèbres, 7, p 682.

7. Mochida O (1991) Spread of freshwater Pomacea snails (Pilidae, Mollusca) from Argentina to Asia. Micronesica Suppl 3, 51-62.

8. Halwart M (1994) The golden apple snail Pomacea canaliculata in Asian rice-farming systems: present impact and future threat. Int J Pest Manag 40, 199-206.

9. Calumpang SMF, Medina MJB, Tejada AW, Medina JR (1995) Environmental impact of two molluscicidal: 
niclosamide and metaldehyde in a rice paddy ecosystem. Bull Environ Contam Toxicol 55, 494-501.

10. Phosawat N (2000) Efficiency of tea seed cake (Camellia sinensis) and derris roots (Derris elliptica) extracts for controlling of golden apple snails (Pomacea canaliculata). MSc thesis, Mahidol Univ.

11. Chaicharoenpong C, Petsom A (2009) Quantitative thin layer chromatographic analysis of the saponins in tea seed meal. Phytochem Anal 20, 253-5.

12. World Health Organization (1965) Molluscicide screening and evaluation. Bull World Health Organ 33, 567-81.

13. Abbott WS (1925) A method of computing the effectiveness of an insecticide. J Econ Entomol 18, 265-7.

14. Finney DJ (1971) Probit Analysis, 3rd edn, Cambridge Univ Press, Cambridge.

15. Huang HC, Liao SC, Chang FR, Kuo YH, Wu YC (2003) Molluscicidal saponins from Sapindus mukorossi, inhibitory agents of golden apple snails, Pomacea canaliculata. J Agr Food Chem 51, 4916-9.

16. Domon B, Hostettmann K (1984) New saponins from Phytolacca dodecandra L'Herit. Helv Chim Acta 67, 1310-5.

17. Nagata T, Tsushida T, Hamaya E, Enoki N, Manabe S, Nishino C (1985) Camellidins, antifungal saponins isolated from Camellia japonica. Agr Biol Chem 49, 1181-6.

18. Sagesaka YH, Watanabe K, Sukata K, Uzawa J (1994) A new glucuronide saponin from tea leave (Camellia sinensis var sinensis). Biosci Biotechnol Biochem 58, 2036-40.

19. Yoshikawa M, Murakami T, Yoshizumi S, Murakami N, Yamahara J, Matsuda H (1996) Bioactive saponins and glycosides. V. Acylated polyhydroxyolean-12-ene triterpene oligoglycosides, camelliasaponins $\mathrm{A}_{1}, \mathrm{~A}_{2}$, $\mathrm{B}_{1}, \mathrm{~B}_{2}, \mathrm{C}_{1}$, and $\mathrm{C}_{2}$, from the seeds of Camellia japonica L.: structures and inhibitory activity on alcohol absorption. Chem Pharmaceut Bull 44, 1899-907.

20. Kitagawa I, Hori K, Motozawa T, Murakami T, Yoshikawa M (1998) Structures of new acylated oleanene-type triterpene oligoglycosides, theasaponins $\mathrm{E}_{1}$ and $\mathrm{E}_{2}$, from the seeds of tea plant, Camellia sinensis (L.) O. KunTZE. Chem Pharmaceut Bull 46, 1901-6.

21. Murakami T, Nakamura J, Matsuda H, Yoshikawa M (1999) Bioactive saponins and glycosides. XV. Saponin constituents with gastroprotective effect from the seeds of tea plant, Camellia sinensis L. var. assamica PIERRE, cultivated in Sri Lanka: structure of assamsaponins A, B, C, D, and E. Chem Pharmaceut Bull 47, 1759-64.

22. Murakami T, Nakamura J, Kageura T, Matsuda H, Yoshikawa M (2000) Bioactive saponins and glycosides. XVII. Inhibitory effect on gastric emptying and accelerating effect on gastrointestinal transit of tea saponins: structures of assamsaponins F, G, H, I, and $\mathrm{J}$ from the seeds and leaves of the tea plant. Chem Pharmaceut Bull 48, 1720-5.
23. Lu Y, Umeda T, Yagi A, Sakata K, Chaudhuri T, Ganguly DK, Sarma S (2000) Triterpenoid saponins from the roots of tea plant (Camellia sinensis var. assamica). Phytochemistry 53, 941-6.

24. Li B, Luo Y (2003) Studies on chemical constituents of Camellia oleifera Abel. Chem J Internet 5, 20.

25. Hostettmann K, Marston A (2005) Saponins. Chemistry and Pharmacology of Natural Products, Cambridge Univ Press, Cambridge, pp 144-6.

26. Olugbenga AM, Musa AE, Oluwatoyin AH (2012) Toxicological activity of crude saponin extract of Ficus platyphylla. Asian J Pharmaceut Clin Res 5 Suppl 1, 30-3. 